\title{
Study and modelling of anodized 2618 aluminum behavior subjected to multiaxial fatigue
}

\author{
Benaissa Malek ${ }^{*}$, Catherine Mabru and Michel Chaussumier \\ Université de Toulouse, Institut Clément Ader (ICA), UMR CNRS 5312, UPS/INSA/ISAE/ Mines Albi, 3 rue Caroline \\ Aigle, 31400 Toulouse, France.
}

\begin{abstract}
Anodized Aluminum alloys are widely used in aeronautic construction due to their specific mechanical properties. However, anodization process often leads to a decrease of the fatigue resistance of the alloys. In order to identify and characterize the different mechanisms involved in the detrimental effect of anodization of 2618-T851 alloy on its fatigue life and to determine the impact of loading nature, several tests have been performed on specimens with different surface states at various stress ratios. It was found that roughness of machining has no effect unlike the stress ratio or mean stress in tensile tests. The tests on the pickled, anodized, impregnated and sealed specimens showed it was the anodic oxidation step which was the more detrimental for fatigue resistance under tensile loading comparing to the other steps. It has been also observed that no such detrimental effect occurred under torsion loading. Concerning the prediction of fatigue life, two critical plane-based analysis approaches have been used (Morel and Fatemi-Socie criteria) to make fatigue life prediction for uniaxial and multiaxial fatigue test. Comparisons showed that both criteria gives overestimated fatigue life for uniaxial tensile loading under compression mean stress and underestimated fatigue life for tensile-torsion in phase loading.
\end{abstract}

\section{Introduction}

In many situations (especially in aircraft construction), it is necessary to modify the surface of previously machined parts by anodizing treatment to improve wear resistance and/or corrosion resistance of aluminum alloys [1]. Anodizing treatment is a successive multi-steps process including: degreasing, pickling, anodic oxidation (growth of anodic film), potentially impregnation and sealing.

However, anodizing treatment may reduce the fatigue resistance $[2,3]$ and the effect of this surface treatment on the fatigue behavior of aluminum alloys has been extensively studied [2, 3 , 4 , 5]. According to numerous researchers, the anodic oxidation process can modify the metallurgical composition, the micro-geometry and also internal stresses of the surface. This usually leads to the degradation of the fatigue resistance for aluminum alloys $[4,6,7]$.

The available literature in this area has provided evidence that the fatigue life decrease can be related to the brittle properties of the aluminum oxide [3], to the film thickness $[8,9]$, the type of anodizing process $[2,6,8]$, surface pre-treatment $[10,11]$, sealing step after anodizing [12] and/or substrate microstructure [13].

For 2014 alloy, it has been shown that fatigue cracks of hard anodized samples initiated in the coating in high stress regions and in the interface between coating and substrate in low stress regions [3].

Depending on aluminum alloy microstructure and pickling pre-treatment conditions, several pits could be produced due to galvanic coupling between intermetallic particles and aluminum matrix promoting the dissolution of intermetallic particles or surrounding aluminum matrix. This creates surface defects acting as stress concentrators that promote the initiation of many small fatigue cracks and leads to fatigue resistance decrease $[13,14,15$, 16]. In the case of 2017 alloy, the decrease in fatigue life can also be associated to the brittle nature of the oxide particles containing copper and accumulated at the interface which enhances crack initiation and propagation [13]. In the case of $2 \mathrm{~A} 12$ and 2024 aluminum alloys, it 
has been shown that the reduction of its fatigue resistance was principally influenced by anodization treatment creating internal stresses at the interface between the substrate and the anodic layer which resulted in a crack initiation from the interface $[2,6]$.

Fatigue tests on 2214 aluminum alloy [4], performed on degreased, anodized and sealed specimens have shown that the reduction of the fatigue resistance of 2214 alloy is due to the anodic oxidation-sealing phase. It was observed that anodic layer crazed under fatigue loading and failure occurred from multi-crack initiation sites.

In addition, the nature of loading seems also to have an influence of the effect of anodizing treatment on the fatigue resistance. A reduction of fatigue resistance have been seen on anodized 2014 aluminum alloy subjected to tension fatigue tests, even though the anodized film did not affect the fatigue behavior under the rotating-bending fatigue tests. Under tensile fatigue test, the fatigue resistance of anodized specimen is controlled by the crack initiation behavior in the substrate induced by the rupture of anodized film related to the deformation of substrate during fatigue process [17].

From these various works on 2000 alloys series, it appears that the decrease of the fatigue resistance depends on the anodizing treatment, the loading nature and on the alloy itself. Moreover, all the previous studies deal with the influence of anodization process with respect to uniaxial fatigue. However, industrial parts are often submitted to multiaxial loading in service.

The purpose of the present research project is therefore to quantify the impact of loading nature, surface roughness and anodizing process on fatigue behavior of 2618 alloy and finally to analyze the prediction life models for multiaxial loading and extend them to anodized specimens. In this aim, the fatigue resistance of the bare alloy and then the fatigue behavior of the anodized alloy, considering successively uniaxial and multiaxial loadings is investigated.

The first part of this paper is then devoted to study the fatigue resistance of machined specimens especially regarding surface roughness which can be affected by the surface treatment and has been proved to be able to lead to a decrease of the fatigue resistance [14]. The effect of stress ratio is also investigated in order to prepare multiaxial fatigue modeling. The influence of the different steps of the anodizing process is presented in a second part. At last, these preliminary results are used in two multiaxial fatigue models in order to estimate the fatigue life in the case of tensile-torsion tests.

\section{Material and experimental procedures}

The material investigated is 2618-T851 aluminumcopper alloy characterized by high mechanical characteristics and low density. The chemical composition is presented on table 1 and the main mechanical properties in table 2 .
Table 1: Chemical composition ( $\mathrm{m} \%$ ) of 2618 alloy heated at $530^{\circ} \mathrm{C}$ during 24 hours [18].

\begin{tabular}{|c|c|c|c|c|c|c|}
\hline $\mathbf{C u}$ & $\mathbf{F e}$ & $\mathbf{M g}$ & $\mathbf{S i}$ & $\mathbf{N i}$ & $\mathbf{T i}$ & $\mathbf{Z n}$ \\
\hline $1,9-$ & $0,9-$ & $1,3-$ & $0,1-$ & $0,9-$ & $0,04-$ & 0,1 \\
2,7 & 1,3 & 1,8 & 0,25 & 1,2 & 0,1 & \\
\hline
\end{tabular}

Table 2: Mechanical properties of 2618-T851 alloy.

\begin{tabular}{|c|c|c|c|}
\hline $\begin{array}{c}\text { Young } \\
\text { modulus E } \\
(\mathbf{G P a})\end{array}$ & $\begin{array}{c}\mathbf{R}_{\mathrm{m}} \\
(\mathbf{M P a})\end{array}$ & $\begin{array}{c}\mathbf{R}_{\mathrm{p} 0,2} \\
(\mathbf{M P a})\end{array}$ & $\begin{array}{c}\text { Shear } \\
\text { modulus G } \\
(\mathbf{G P a})\end{array}$ \\
\hline 72 & 432 & 372 & 27 \\
\hline
\end{tabular}

The different steps of heat treatment of the alloy are shown in figure 1. It has also a good resistance in temperature [19] but the corrosion resistance properties of this alloy are bad [20].

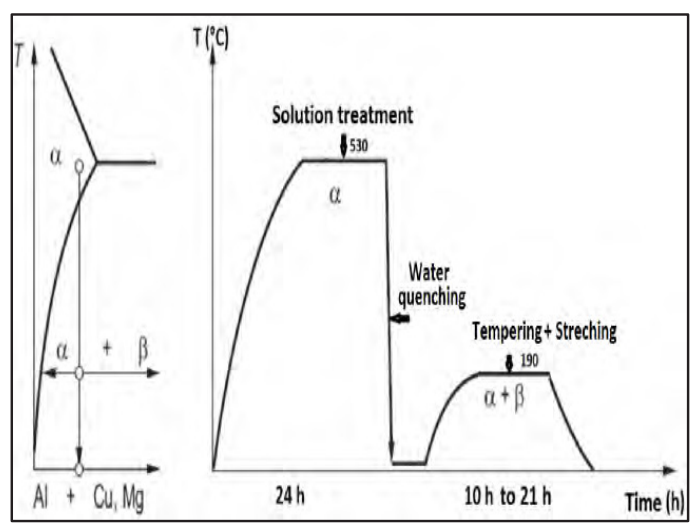

Fig.1. Heat treatment of 2618-T851 alloy.

In terms of the microstructure, 2618-T851 alloy is characterized by the presence of many various intermetallic precipitates localized in grains and grain boundaries as shown in figure 2 .

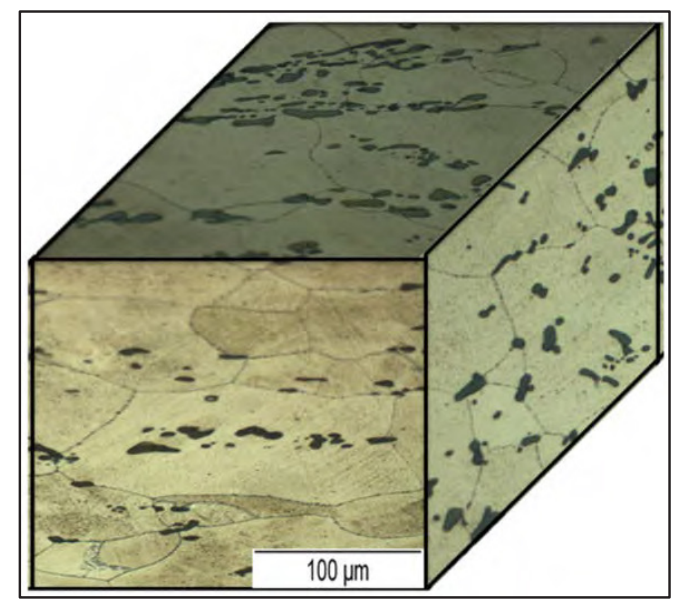

Fig.2. Microstructure of 2618-T851 alloy.

The density of those intermetallic particles is very important and they are rich on aluminum, iron, nickel and copper which is consistent with other works on this alloy [21]. The intermetallic particles are rod-shaped with a size between 1 and $10 \mu \mathrm{m}$. Surface treatments have been performed by IRT M2P (Institut de Recherches Technologiques : Matériaux Métallurgie et Procédés). They are divided into five steps (table 3 ) in order to get rid of 
superficial layer, to obtain good corrosion and wear resistance and to strengthen weak areas of the layer.

Table 3: Parameters of different surface treatments processes of 2618-T851 alloy.

\begin{tabular}{|c|c|c|c|}
\hline Process & Bath nature & $\begin{array}{c}\text { Temp } \\
\left({ }^{\circ} \mathbf{C}\right)\end{array}$ & $\begin{array}{c}\text { Time } \\
(\mathbf{m i n})\end{array}$ \\
\hline Degreasing & $\begin{array}{c}\text { Sococlean } \\
\text { A3431 } 10 \%\end{array}$ & 45 & 6 \\
\hline Pickling & $\begin{array}{c}\text { Socosurf } \\
\text { A1858/A1806 }\end{array}$ & 50 & 10 \\
\hline Anodization & $\begin{array}{c}\text { Sulfuric acid } \\
200 \mathrm{~g} / \mathrm{L}(15 \mathrm{~V})\end{array}$ & 18 & 40 \\
\hline Impregnation & $\begin{array}{c}\text { Lanthane } \\
613.3\end{array}$ & 40 & 20 \\
\hline Sealing & $\mathrm{H}_{2} \mathrm{O}$ & $98-100$ & 30 \\
\hline \multicolumn{3}{|c}{}
\end{tabular}

All fatigue tests were performed using cylindrical specimens on a MTS hydraulic multiaxial fatigue machine. Fatigue behavior under uniaxial and multiaxial with constant amplitude was investigated in a preliminary study in tensile and/or torsion at room temperature. The different arithmetic roughness values of the specimens were $0.8,3.2$ and $6.3 \mu \mathrm{m}$. Tests have been carried out with different stress ratios $(0.1,-1$ and -2$)$ and the frequency of all the tests is 10 Hertz.

The specimen geometry and dimensions are given in Fig.3.

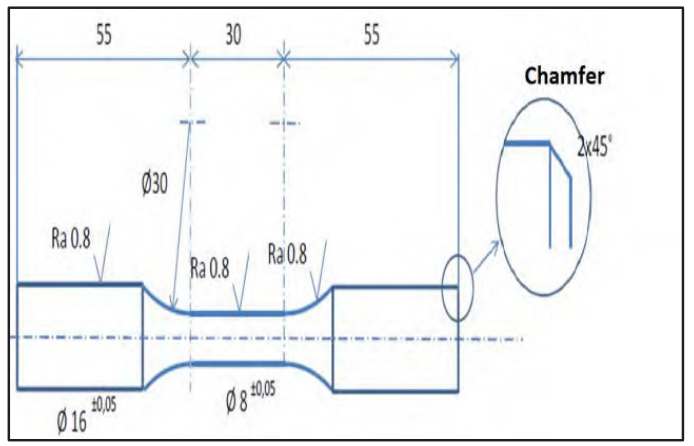

Fig.3. Cylindrical specimen geometry. All dimensions are given in $\mathrm{mm}$.

Same fatigue tests have been conducted on treated specimens with a roughness level of $0.8 \mu \mathrm{m}$ in order to analyze the effect of each step of the process on the fatigue resistance decrease. Some specimens have been only degreased and pickled, some others have been degreased, pickled and anodized; a third group of specimens has been degreased, pickled, anodized and then impregnated; a last group of specimens have been completely treated (i.e. degreased, pickled, anodized, impregnated and sealed).

\section{Results and discussion}

\subsection{Machined specimens}

Fatigue tests have been performed for lives between $10^{4}$ and $10^{7}$ cycles in order to characterize the material parameters needed in the chosen multiaxial fatigue criteria.

\subsubsection{Effect of surface roughness}

The two following figures (Fig. 4 and 5) show the fatigue test results for the two fatigue loading: uniaxial tension with a stress ratio of 0.1 and torsion with a stress ratio of -1 .

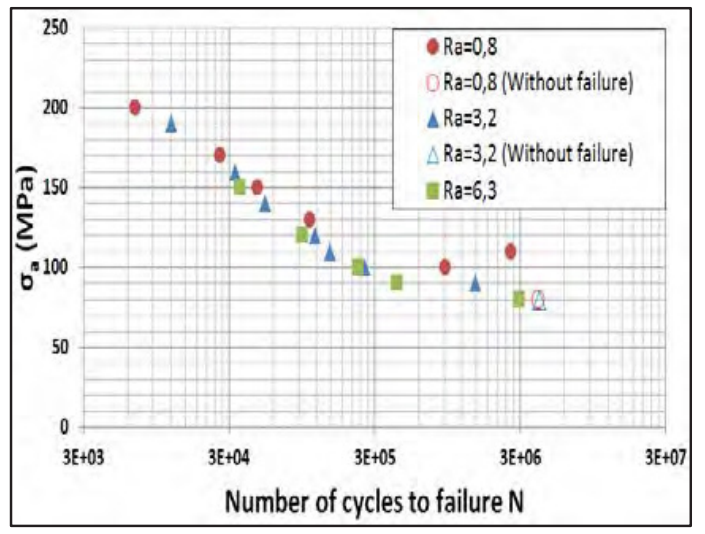

Fig.4. Fatigue test results in tension with different roughness levels, $\mathrm{R}=0.1$.

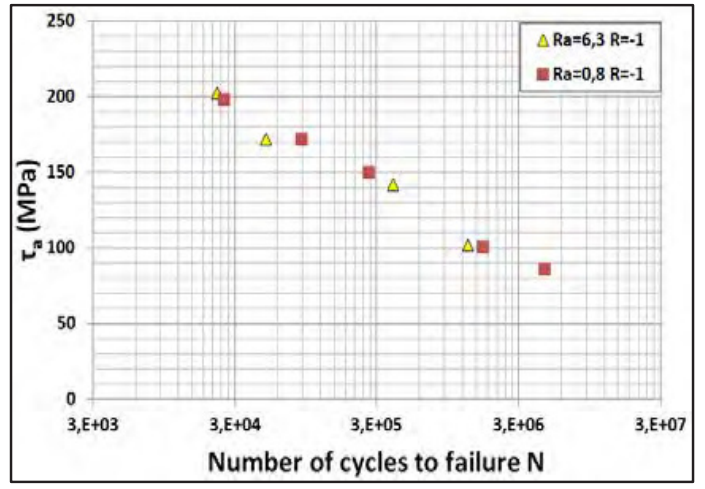

Fig.5. Fatigue test results in torsion with different roughness levels, $\mathrm{R}=-1$.

It appears that roughness level of machined specimens has no effect on the behavior of 2618 alloy whatever the stress level is. It can be concluded that fatigue resistance in not sensitive to surface roughness unlike 2214 aluminum-copper alloy which showed an important sensitivity to surface roughness [14].

These first results suggest that one or both of the two other surface characteristics (metallurgy and residual stresses) is/are the governing factor(s) in fatigue failure. The influence of metallurgy can be intuitively deduced from metallurgical observation which indicated the presence of numerous rodshaped intermetallic particles inhomogeneously distributed in the material $[21,22]$.

\subsubsection{Effect of load ratio}

Uniaxial tensile fatigue tests with various stress ratios have been carried out on machined specimens with arithmetic roughness of $0.8 \mu \mathrm{m}$. Fig. 6 illustrates the obtained results for stress ratio of 0.1 and -2 . 


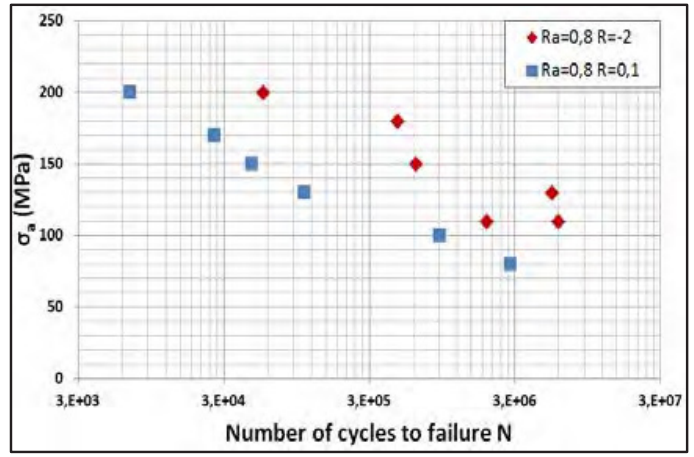

Fig.6. Fatigue test results in tension with different load ratios, $\mathrm{Ra}=0.8 \mu \mathrm{m}$.

The mean stress has an effect on the number of cycles to failure as for numerous metallic alloys $[16,17]$.

\subsection{Surface treated specimens}

As mentioned above, fatigue tests were carried out after each step of the whole anodizing process (table 3) on machined specimens with an initial roughness of $0.8 \mu \mathrm{m}$.

The objective is to characterize the effect of each step of the anodization process on fatigue life and to define which one is the detrimental step of the whole process and leads to a decrease of the fatigue resistance.

Fig. 7 and 8 show the obtained results for tensile and torsion fatigue tests respectively.

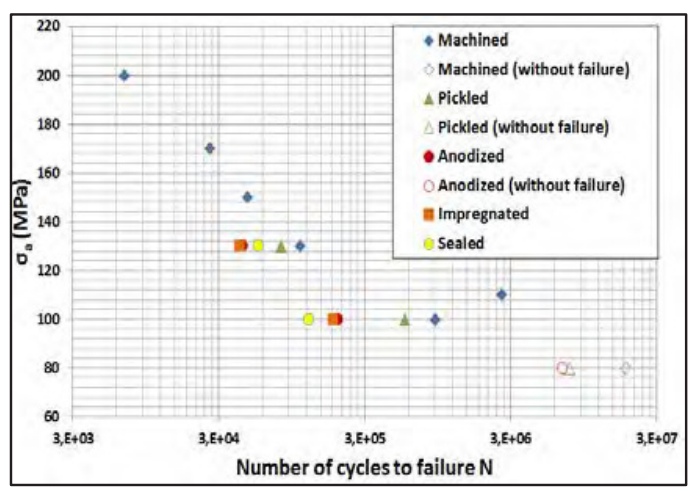

Fig.7. Fatigue tests in tension with different surface treatments, $\mathrm{R}=0.1$ and $\mathrm{Ra}=0.8 \mu \mathrm{m}$.

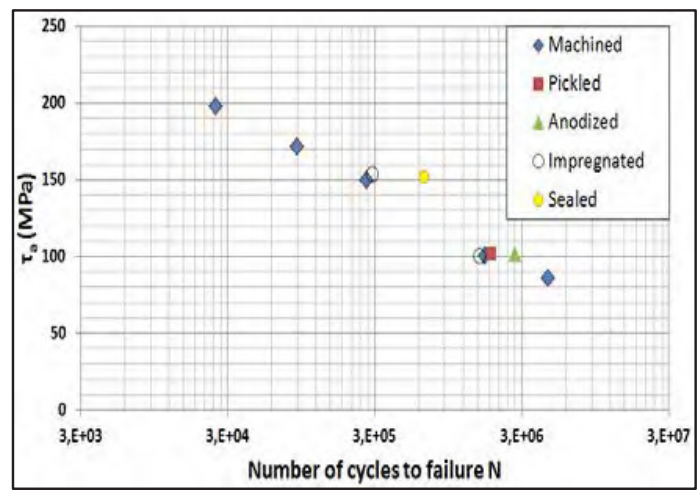

Fig.8. Fatigue test results in torsion with different surface treatments, $\mathrm{R}=-1$ and $\mathrm{Ra}=0.8 \mu \mathrm{m}$.
Under tensile fatigue tests, it appears that the main part of the fatigue resistance decrease is mainly due to anodic oxidation: degreasing and pickling have slight influence as it was also observed for 2214 alloy treated with similar conditions [14].

In addition, it seems that impregnation or sealing have quite negligible influence comparing to anodic oxidation.

Preliminary results for torsion fatigue tests show that there is no detrimental effect of the successive surface treatment steps on the fatigue life. It can be concluded that fatigue resistance decrease is mainly due to the anodic oxidation step combined with nature of the loading.

\subsection{Fracture surfaces}

Some initial observations were made to identify the different modes of fracture of machined and impregnated specimens. The main microscopic fracture features are a combination of ductile intergranular and transgranular fracture. Fracture surfaces of machined specimens exhibit multiple initiation sites. On the contrary, fracture surfaces of impregnated specimens show the existence of a unique crack initiation site associated with cracks in the anodic layer, as shown in Fig. 9. As no crack is observed in other parts of the anodic layer, it could suggest that the fatigue crack initiated from this impregnated layer. This has been observed for tensile and torsion tests indicating an effect of anodization treatment on the mechanisms of crack initiation for both loadings. This is quite surprising concerning torsion as no effect of surface treatment on fatigue life has been detected (Fig. 8).

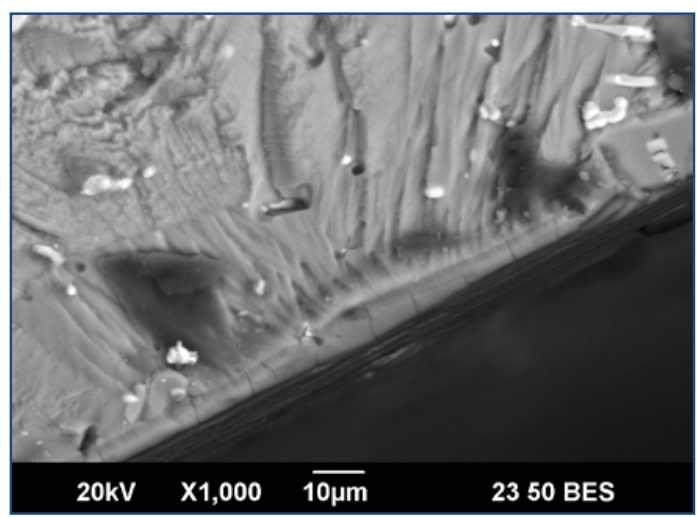

Fig.9. Fracture surfaces of an impregnated specimen tested in torsion, $\tau_{\mathrm{a}}=150 \mathrm{MPa}, \mathrm{Ra}=0.8 \mu \mathrm{m}$ and $\mathrm{R}=-1$.

\subsection{Fatigue life predictions}

Critical plane-based fatigue life analyses were performed using Morel [28] and Fatemi-Socie [26] models to predict fatigue life of machined specimens in medium cycle fatigue regime for multiaxial loadings in phase with sinusoidal signal and constant amplitude.

\subsubsection{Morel's model}

In the high cycle fatigue regime, as crack initiation phenomenon takes place at the scale of a few grains, a damage variable at this scale is introduced. 
Morel considers accumulated plastic mesostrain on a critical plane as the damage variable. In this model, a crack is considered to be initiated when the damage variable reaches a critical value [25, 27].

The criterion is written as:

$$
\max _{\theta, \varphi}\left(T_{\sigma}(\theta, \varphi)+\alpha \cdot P_{\max }\right) \leq \beta
$$

where:

$\mathrm{P}_{\max }$ is the maximum mesoscopic (equal to the macroscopic) hydrostatic stress,

$\mathrm{T}_{\sigma}(\theta, \varphi)$ is the damage parameter proportional to an upper bound of the plastic mesostrain accumulated on an elementary material shear plane $\Delta$ (also average value of $\mathrm{T}_{\mathrm{a}}$ ), it is a function of the orientation of this plane through the angles $\theta$ and $\varphi$.

This parameter is estimated by an integration carried out through the whole area of the plane $\Delta$ [30]:

$$
T_{\sigma}(\theta, \varphi)=\sqrt{\int_{\psi=0}^{2 \pi} T_{a}^{2}}(\theta, \varphi, \psi) d \psi
$$

Where $T_{a}$ is the amplitude of the macroscopic resolved shear stress acting on a line of the plane $\Delta$ directed by $\mathbf{m}$ as showed in Fig. 10. This line is located by the angle $\psi$ that makes with respect to an arbitrary but fixed axis in $\Delta$ [27].

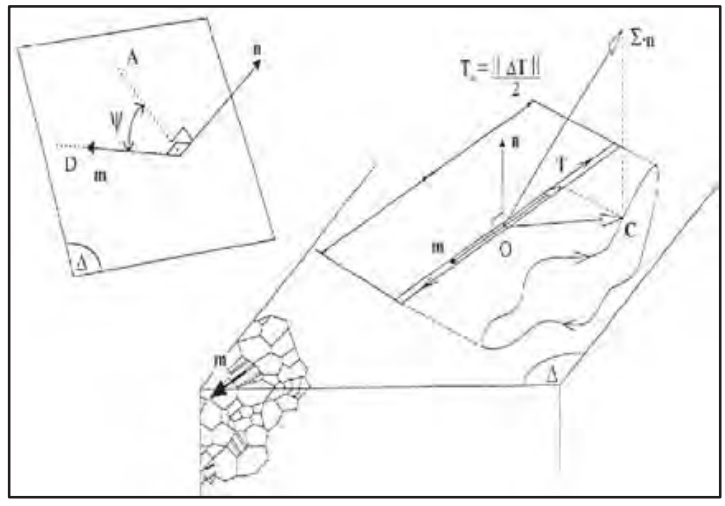

Fig.10. Path of the macroscopic shear stress $\mathrm{C}$ acting on $\Delta$ and corresponding path of $\mathrm{T}$ acting on an easy glide direction $\mathbf{m}[25]$.

The parameters $\alpha$ and $\beta$ can be related to the fatigue limits of two standard fatigue tests, e.g. tensilecompression with a stress ratio $\mathrm{R}, \mathrm{s}_{\mathrm{R}}$, and fully reversed torsion, $\mathrm{t}$ :

$$
\beta=\sqrt{\pi} t \quad \alpha=\frac{\sqrt{\pi}\left(t-\frac{s_{R}}{(1-R)}\right)}{\frac{2 S_{R}}{3(1-R)}}
$$

where ' $\mathrm{S}_{\mathrm{R}}$ ' and ' $\mathrm{t}$ ' represent respectively the fatigue resistance in tensile test under stress ratio $R$ and in fully reversed torsion.

Fig. 11 shows the result of identification of Morel model parameters from experimental from fitted S$\mathrm{N}$ curves obtained from uniaxial loading in tension $(\mathrm{R}=0.1)$ and torsion $(\mathrm{R}=-1)$.

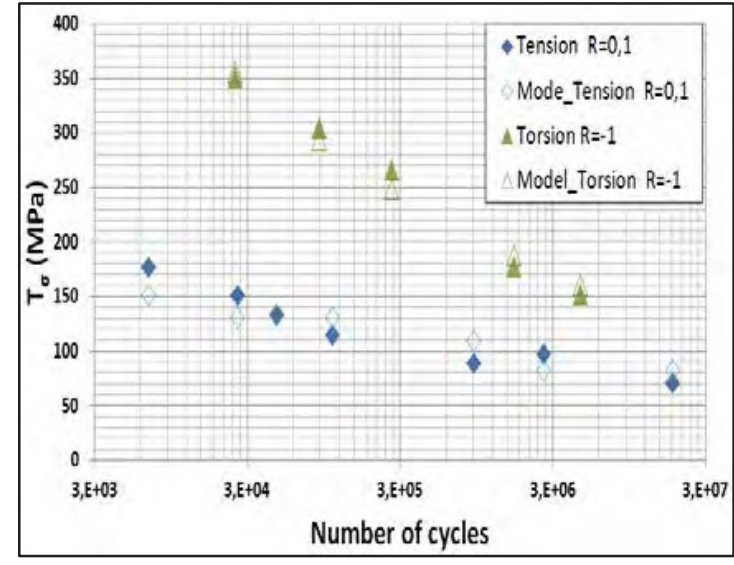

Fig.11. $\mathrm{T}_{\sigma}-\mathrm{N}$ curve corresponding to Morel model and the experimental data, $\mathrm{Ra}=0.8 \mu \mathrm{m}$ and $\mathrm{f}=10 \mathrm{~Hz}$.

\subsubsection{Fatemi-Socie model}

It is usually argued and accepted that fatigue crack initiation involves localized plastic deformation in persistent slip bands even in the high cycle fatigue region [26].

Fatemi-Socie critical plane approach is based on the physical interpretation of fatigue damage. This latter is supposed to be governed by the maximum shear stress amplitude $\left(\Delta \gamma_{\max } / 2\right)$ and the maximum normal stress $\left(\sigma_{n, \max }\right)$ that are expressed on the model by the equation 4 below:

$$
\frac{\Delta \gamma_{\max }}{2}\left(1+k \frac{\sigma_{n, \max }}{s_{y}}\right)=\mathrm{constant}
$$

where:

$\mathrm{S}_{\mathrm{y}}$ is the material monotonic yield strength; it serves to normalize the maximum normal stress in order to preserve a dimensionless term,

$\mathrm{k}$ is a material constant depending on number of cycles to failure.

Equation 4 can be written in terms of shear strainlife properties obtained from fully reversed torsion tests [28, 29] as:

$$
\frac{\Delta \gamma_{\max }}{2}\left(1+\mathrm{k} \frac{\sigma_{\mathrm{n}, \max }}{\mathrm{S}_{\mathrm{y}}}\right)=\frac{\tau_{\mathrm{f}}^{\prime}}{\mathrm{G}}\left(2 \mathrm{~N}_{\mathrm{f}}\right)^{\mathrm{bo}}+\gamma_{\mathrm{f}}^{\prime}\left(2 \mathrm{~N}_{\mathrm{f}}\right)^{\mathrm{co}}
$$

where:

$\mathrm{G}$ is the shear modulus, $\tau_{f}^{\prime}$ is the shear fatigue strength coefficient, $\gamma_{f}^{\prime}$ is the shear fatigue ductility coefficient, $b_{o}$ and $c_{o}$ are shear fatigue strength and shear fatigue ductility exponents, respectively.

Fig. 12 shows the result of identification of FatemiSocie model parameters from experimental tests obtained from uniaxial loading in tension $(\mathrm{R}=0.1)$ and torsion $(\mathrm{R}=-1)$ using the least square on the whole set of fatigue data. 


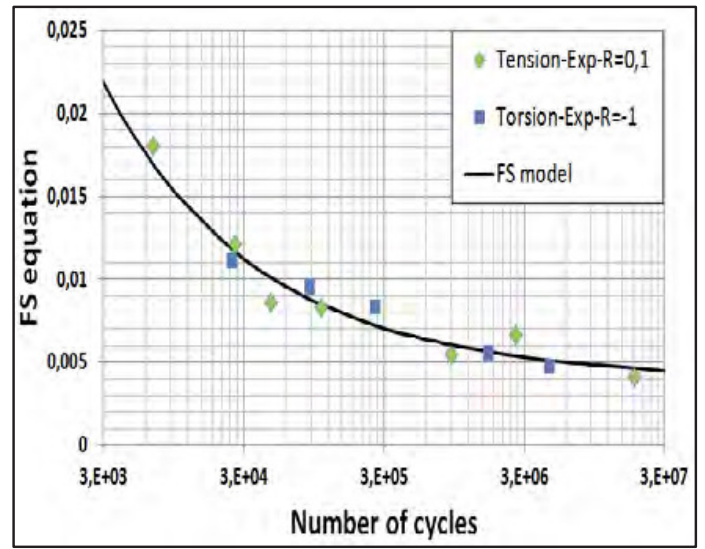

Fig.12. Fatemi-Socie model compared to experimental data, $\mathrm{Ra}=0.8 \mu \mathrm{m}$.

\subsubsection{Fatigue life predictions}

Uniaxial fatigue test results for $\mathrm{R}$ stress ratio equal to -2 have been compared to fatigue life predictions given by both criteria. Some multiaxial fatigue tests have been carried out in tension and torsion in phase and with sinusoidal constant amplitude and results have been also compared to the given predictions. Results of these comparisons are illustrated in Fig. 13 and 14.

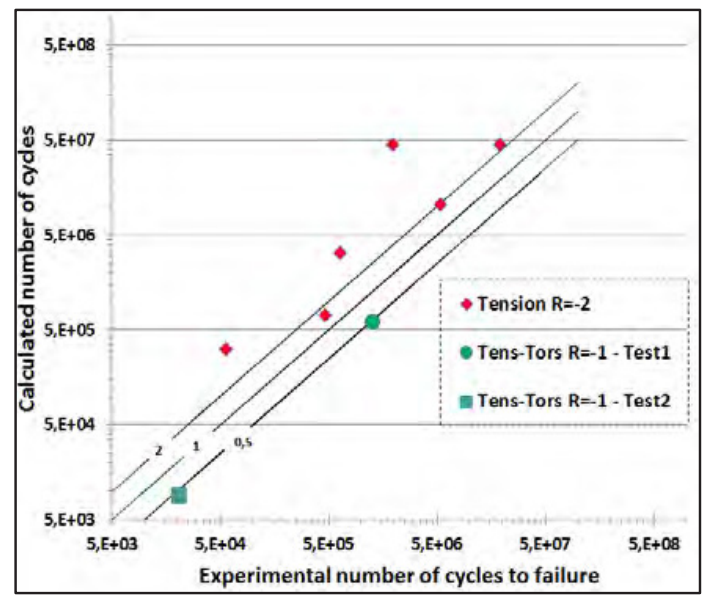

Fig.13. Morel model predicted fatigue life vs experimental fatigue life for multiaxial and uniaxial fatigue tests, $\mathrm{Ra}=0.8 \mu \mathrm{m}$.

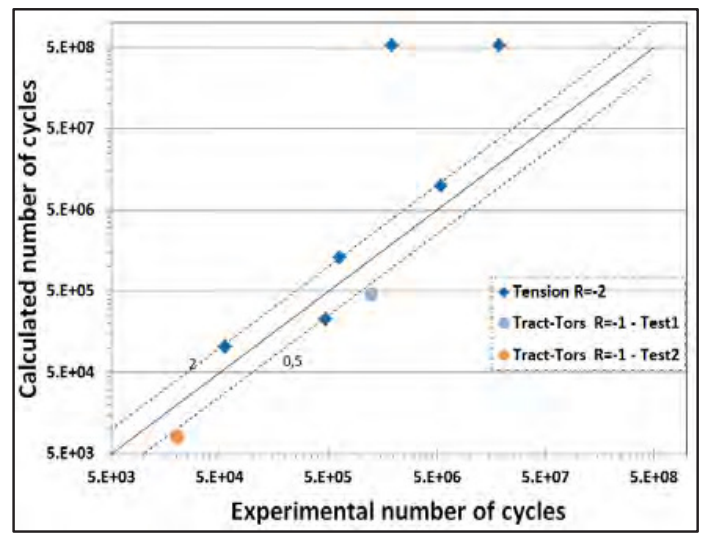

Fig.14. Fatemi-Socie model predicted fatigue life vs experimental fatigue life for multiaxial fatigue tests, $\mathrm{Ra}=0.8 \mu \mathrm{m}$.
Both criteria overestimate the fatigue life for uniaxial tensile test under $\mathrm{R}=-2$. One explanation is that these cases are not in the load ratio range used for material characterization; it would be better to use also these results to perform the fitting of the model. On the contrary, for tension-torsion tests, both criteria give underestimated fatigue life but these predictions are closer to the line $2 \mathrm{~N}$ which can be considered as quite good. More fatigue test will be performed to ensure these first results.

\section{Conclusions and perspectives}

Fatigue resistance of bare and anodized 2618 alloy has been investigated. Tests on machined specimens show that the surface roughness has no effect on fatigue lives. As it was expected, the stress ratio has a high influence in tensile loading.

Fatigue tests performed after each step of the anodizing process show that for fatigue tensile tests, the anodic oxidation step in itself is the main detrimental step of the whole process, leading to a decrease of the fatigue life. The other steps such as degreasing and pickling or impregnation or sealing have no or very slight influence on the fatigue resistance.

However, fatigue resistance of anodized 2618 alloy depends also on the loading nature; no effect of the surface treatment on fatigue life is noticed for torsion tests.

Fracture surfaces analysis has shown the existence of one initiation site with the cracking of the anodic layer while bare specimen exhibited multisite initiation.

Considering multi-axial fatigue life prediction, both Morel's and Fatemi-Socie's criteria seem to give underestimated fatigue life under proportional tensile-torsion loading and overestimated fatigue life for tensile tests under a stress ratio of -2 . More experimental data and analysis are still needed to improve fatigue life prediction.

Further works are currently performed to investigate existing prediction life models for machined specimens by integrating the internal pressure with tension and torsion.

Next work will be devoted to the extension of predicting models to anodized specimens.

Special thanks are given to Université Paul Sabatier (Toulouse) for financial support of this research study and to IRT M2P, in particular Joffrey Tardelli (IRT M2P), Benjamin Mouls (IRT M2P), Cédric Marchetto (IRT M2P) and Aimé Ramakistin (INEOSURF).

\section{References}

[1] S. D, Cramer and B.S. Covino, ASM Handbook, 13, (2003)

[2] B. Nie, Z. Zhang, Z. Zhao and Q. Zhong, Mat Des, 50, 1005-1010 (2013)

[3] R. Sadeler, J Mat Sc, 208, 5803-5812 (2006) 
[4] M. Shahzad, M. Chaussumier, R. Chieragatti, C. Mabru and F. Rezai-Aria, Surf Coat Tech, 206, 2733-2739 (2012)

[5] N. Chahboun, E. Rocca, D. Veys-Renaux, M. Augros, M. Boutoba and N. Caldeira, J Elect Soc, 163, 69-75 (2016)

[6] J. Camargo, H. Voorwald, M. Cioffi and M.Y.P. Costa, Surf Coat Tech, 201, 9448-9455 (2007)

[7] D. Zavodska, E. Tillova, M. Guagliano, L. Kucharikova and M. Chalupova, Mat Tod, 4, 60016006 (2017)

[8] B. Lonyuk, I. Apachitei and J. Duszczyk, Surf Coat Tech, 201, 8688-8694 (2007)

[9] E. Cirik and K. Genel, Surf Coat Tech, 202, 5190-5201 (2008)

[10] M. Chaussumier, C. Mabru, M. Shahzad, R. Chieragatti and F. Rezai-Aria, I J Fatigue, 48, 205213 (2013)

[11] M. Chaussumier, C. Mabru, R. Chieragatti and M. Shahzad, Pro Eng, 66, 300-312 (2013)

[12] X. Zhao, G.Wei, Y. Yu, Y. Guo and A. Zhang, Surf Rev Lett, 22, 1-7 (2015)

[13] C. Fares, L. Hemmouche, M.A. Belouchrani, A. Amrouche, D. Chicot and E.S. Puchi-Cabrera, Mat Des, 86, 723-734 (2015)

[14] M. Shahzad, M. Chaussumier, R. Chieragatti, C. Mabru and F. Rezai-Aria, Surf Coat Tech, 27332739 (2012)

[15] G. E. Thompson, L.C. Zhang, J. E. Smith and P. Skeldon, Corros Sci, 55, 1052-1060 (1999)

[16] B. Priet, G. Odemer, C. Blanc, K. Giffard and L. Arurault, Surf Coat Tech, 307, 206-2019 (2016)

[17] K. Shiozawa, H. Kobayashi, M. Terada and A. Matsui, Jap Soci Mech Eng, 66, 2170-2175 (2000)

[18] I. Özbek, Mat Char, 58, 312-317 (2007)

[19] W. Luo, M. Yan and W. Z. Zhu, J Mat Sci, 37, 2685-2691 (2002)

[20] A. Djakovici, B.F. Dyson and M. Mclean, 2nd International Conference on deformation processing and structure of materials, (2005)

[21] C. Rockenhäuser, S. Schriever, P. Von Hartrott, B. Piesker and B. Skrotzki, Mat Sci Eng, 716, 78-86 (2018)

[22] F. Nový, M. Janeček, and R. Král, J All Comp, 487, 146-151 (2009)

[23] M. Morgantini, D. MacKenzie, T. Comlekci and R-V. Rijswick, Proc Eng, 213, 581-588 (2018)

[24] J. Janousek, M. Baldab and J. Svobodab, App Comp Mech, 7, 31-38 (2013)

[25] F. Morel, Fat Frac Eng Mat Str, 21, 241-256 (1998)

[26] A. Fatemi and D. F.Socie, Fat Frac Eng Mat Str, 11, 149-165 (1998)

[27] F. Morel, N. Ranganathan, J. Petit and A. Bignonnet, Euro Str Integ Soc, 25, 87-100 (1999)

[28] N-R. Gates and A. Fatemi, I J Fat, 100, 322336 (2017)

[29] A. Fatemi, Multixial Stresses, Chapter 10, Multiaxial Fatigue, University of Toledo, Advances in Fatigue and Fracture mechanics, (2014) 